\title{
Influence of monoterpenoids on the growth of freshwater cyanobacteria
}

\author{
Lucyna Balcerzak $^{1}$ (D) $\cdot$ Stanisław Lochyński ${ }^{1,2}$ (D) Jacek Lipok $^{3}$ (D)
}

Received: 7 January 2021 / Revised: 19 March 2021 / Accepted: 30 March 2021 / Published online: 23 June 2021

(C) The Author(s) 2021

\begin{abstract}
Cyanobacteria are characterized by a very high tolerance to environmental factors. They are found in salt water, fresh water, thermal springs, and Antarctic waters. The wide spectrum of habitats suitable for those microorganisms is related to their particularly effective metabolism; resistance to extreme environmental conditions; and the need for only limited environmental resources such as water, carbon dioxide, simple inorganic salts, and light. These metabolic characteristics have led to cyanobacterial blooms and the production of cyanotoxins, justifying research into effective ways to counteract the excessive proliferation of these microorganisms. A new and interesting idea for the immediate reduction of cyanobacterial abundance is to use natural substances with broad-spectrum biological activity to restore phytoplankton diversity. This study describes the effects of selected monoterpenoid derivatives on the development of cyanobacterial cultures. In the course of the study, some compounds $(( \pm)$-citronellal, $(+)-\alpha$-pinene) showed the ability to inhibit the colonization of the tested photosynthetic bacteria, while others (eugenol, eucalyptol) stimulated the growth of these microorganisms. By analyzing the results of these experiments, information was obtained on the mutual relations of cyanobacteria and the tested monoterpenes, which are present in the aquatic environment.
\end{abstract}

\section{Key points}

- Monoterpenoids significantly inhibit the growth of single cyanobacterial strains.

- Monoterpenoids can inhibit the growth of cyanobacterial consortia.

- Natural substances can control the growth of freshwater cyanobacteria.

Keywords Cyanobacteria $\cdot$ Monoterpenoid $\cdot$ Inhibition of growth $\cdot$ Bloom formation $\cdot$ Cyanobacterial consortium

\section{Introduction}

Cyanobacteria in principle require only water, carbon dioxide, inorganic substances, and light to live (Fay 1965; Vioque 2007). These limited environmental requirements make blue-green algae pioneer microorganisms; they occur most

Lucyna Balcerzak

lucyna.balcerzak@pwr.edu.pl

1 Department of Chemical Biology and Bioimaging, Faculty of Chemistry, Wroclaw University of Science and Technology, Wyb. Wyspiańskiego 27, 50-370 Wrocław, Poland

2 Institute of Cosmetology, Wrocław College of Physiotherapy, Wrocław, Poland

3 Department of Pharmacy and Ecological Chemistry, Faculty of Chemistry, Opole University, Opole, Poland frequently in freshwater and marine environments but can also be found in damp soil, in hot springs, on bare rock, on soil, and even on Antarctic rocks (Rothschild and Mancinelli 2001; Alwathnani and Johansen 2011; Schopf 2012; Waajen et al. 2014). Moreover, blue-green algae show a very high tolerance to environmental factors and are known to form water blooms in response to even slightly better growth conditions. Among the main causes of blooms are high concentrations of phosphorus and nitrogen (Harke et al. 2012; Jiang et al. 2014). Additionally, many other factors, including light intensity, $\mathrm{pH}$, temperature, and turbulence, influence bloom formation (de Figueiredo et al. 2004; de Souza Santos et al. 2011; Dai et al. 2012; Soares et al. 2013). The main species responsible for problems with bloom toxicity is Microcystis aeruginosa. These cyanobacteria commonly occur in Europe, Asia, and North America (Bláhová et al. 2013). Kormas et al. 2011 indicated the presence of this species among others, which 
create typical cyanobacterial consortia; these species include Aphanocapsa incerta, Chroococcus limneticus, Microcystis flos-aquae, Microcystis aeruginosa, Snowella lacustris, Synechococcus spp., Limnothrix redekei, Jaaginema sp., Oscillatoria sp., Planktolyngbya circumcreta, Planktothrix agardhii, Anabaena flos-aquae, Anabaena aphanizomenoides, and Aphanizomenon issatshenkoi (Kormas et al. 2011). Some other species responsible for bloom formation include Cylindrospermopsis raciborskii in tropical regions (Sinha et al. 2012) and Planktothrix sp. in Europe and South America (Bonilla et al. 2012).

A massive and serious environmental problem is cyanobacterial water bloom as a result of eutrophication (O'Neil et al. 2012; Paerl and Paul 2012). The formation of cyanobacterial blooms in fresh water is a serious problem in the management of drinking water and causes odors in the water during the summer months, thus reducing the attractiveness of tourist destinations (Heisler et al. 2008; Dai et al. 2012). Many species produce toxic compounds such as neurotoxins (homoanatoxin-a, anatoxin-a, anatoxin-a(s), and saxitoxins) (Codd 2000), hepatotoxins (cylindrospermopsin, nodularin, and microcystins), and dermatotoxins (lipopolysaccharides, aplysiatoxins, and lyngbyatoxin-a) (Dawson 1998; Rastogi and Sinha 2009; Kormas et al. 2011; Bittencourt-Oliveira et al. 2012; O'Neil et al. 2012). Cyanobacterial toxins are dangerous for people and other animals since they may cause staggering, hypersalivation, muscle fasciculations, gasping, liver damage, skin irritation, or muscle paralysis (Codd 2000).

Currently, there are several methods to remove cyanotoxins from drinking water, including activated carbon, slow sand filtration, ozonation, membrane filtration, coagulation, chlorination, UV irradiation of water, and bioaccumulation of MC-LR (microcystin-LR) in aquatic macrophytes (Jurczak et al. 2005; Sharma et al. 2012). Some research has been conducted on the inhibition of cyanobacterial growth by nanocrystals (Fan et al. 2019), riparian tree leaf extract (Le Rouzic et al. 2016), and Cu-nanoparticle-embedded biochar composite ( $\mathrm{Li}$ et al. 2019). However, these methods of water treatment possess serious disadvantages: they are very expensive, require appropriate equipment, may have low efficiency, require lengthy treatment, and very often are not available to poor countries or people with ponds (Nimptsch et al. 2008). Thus, there is a real need to find a safer, more effective, and economically accepted method to control harmful cyanobacterial blooms.

In our experiments, the influence of selected monoterpenoids on the growth of freshwater cyanobacteria was studied to verify how these natural substances interact with blue-green algae. Monoterpenoids compose the largest and most structurally diverse class of terpenes (Degenhardt et al. 2009; Groussin and Antoniotti 2012). Most of these substances are common in nature as plant metabolites; additionally, some monoterpenes are cheap and readily available, as they are often considered byproducts of the food, pharmaceutical, or cosmetic industries (Groussin and Antoniotti 2012). These attributes, together with their wellknown biological activity, make monoterpenoids ideal substrates for experiments to investigate their influence on the growth of cyanobacteria.

Specifically, in this article, we show the influence of citral, $( \pm)$-citronellal, $( \pm)$-citronellol, eugenol, $(+)$-carvone, $(+)$ dihydrocarvone, (+)- $\alpha$-pinene, eucalyptol, and (+)-3-carene (Fig. S1) on the growth of Anabaena sp., Chroococcus minutus, and Nodularia moravica.

\section{Materials and methods}

\section{Test organisms and culture conditions}

Strains of the cyanobacteria Anabaena sp. PCC 7937 TISCHER/UTEX 1444 (strain CCALA 007), Chroococcus minutus HINDAK 1969/23 (strain CCALA 055), and Nodularia moravica HINDAK 2000/17 (strain CCALA 797) were obtained from the Institute of Botany, Academy of Sciences of the Czech Republic. Cultures were grown in BG11 medium (ATCC 616) at a temperature of $24 \pm 1{ }^{\circ} \mathrm{C}$ and a photoperiod of 16-8 light-dark with a light intensity of 300 $\mu \mathrm{mol} \cdot \mathrm{m}^{-2} \cdot \mathrm{s}^{-1}$.

\section{Survival cultures}

Survival cultures were made in sterile 250-mL Erlenmeyer flasks containing $50 \mathrm{~mL}$ of BG11 medium (ATCC 616). Cultures were revitalized every 21 days by transferring $10-\mathrm{mL}$ aliquots to fresh medium.

\section{Measurement of total chlorophyll content}

The determination of the growth of the examined photoautotrophs was performed using time-course measurements of total chlorophyll content in experimental cultures. Therefore, at 3-4-day intervals, growth was followed by harvest as follows: $1 \mathrm{~mL}$ of solution was taken from each culture, and the cells were sedimented via centrifugation $(5 \mathrm{~min}, 13,000 \times g)$. The $0.9-\mathrm{mL}$ volumes of supernatant were removed from the samples, and the remaining cells were resuspended in $0.9 \mathrm{~mL}$ of methanol. The samples were shaken for $20 \mathrm{~s}$ and placed in darkness. After $10 \mathrm{~min}$, the content was shaken again for $20 \mathrm{~s}$ and placed in darkness. After 10 more minutes, the samples were centrifuged as above, and total chlorophyll content in the supernatant was determined spectrophotometrically on the basis of Arnon's formula-total chlorophyll $[a+b]=20.21 \cdot E_{645}+$ $8.02 \cdot E_{663}$ (Porra 2002) using a Hitachi (Tokyo, Japan) U 2810 spectrophotometer. The average chlorophyll levels in 

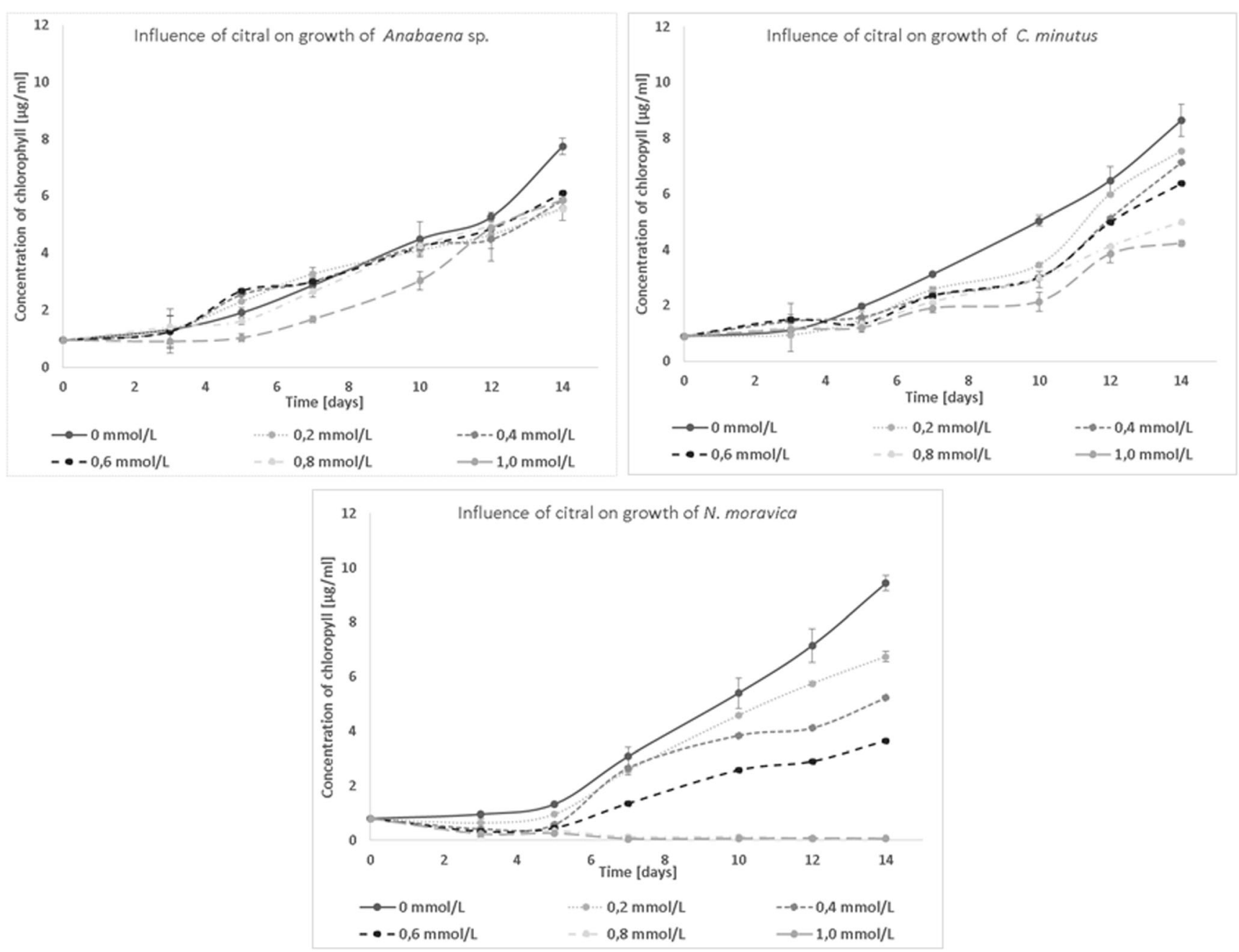

Fig. 1 Influence of citral on the growth of freshwater cyanobacteria

each replicate of the experimental or control culture correlated with the day of the experiment and were plotted based on a time course, yielding growth curves.

\section{Experimental cultures}

The experimental cultures were prepared by transferring appropriate volumes of aliquots from 3-week-old subcultures to fresh media. In this case, the experimental cultures were concentrated via centrifugation (1 $\mathrm{min}, 5000 \mathrm{rpm})$. Then, total chlorophyll content was measured. The volumes of the inocula for each strain were established experimentally based on the final chlorophyll concentration, which was $1 \mu \mathrm{g} / \mathrm{mL}$. Experimental cultures were prepared in 250-mL Erlenmeyer flasks by adding appropriate amounts of each substrate to reach final concentrations of $0.2,0.4,0.6,0.8$, and $1 \mathrm{mM}$ in $50 \mathrm{~mL}$ of culture containing $1 \mu \mathrm{g}$ of chlorophyll per $1 \mathrm{~mL}$ of volume in medium. To obtain a homogenous dispersion of hydrophobic monoterpenoids in the aqueous microbial cultures, the examined compounds were dissolved in $0.15 \mathrm{~mL}$ of acetone - this volume of acetone was experimentally proven to not influence the growth of cyanobacteria - and then added to the culture. Cultures containing only acetone and no monoterpenoids served as controls.

All experiments or controls had at least three repetitions. The influence of monoterpenoids on the growth of the examined cyanobacteria was determined via time-course measurements of total chlorophyll content in experimental cultures in relation to the appropriate control. Therefore, total chlorophyll content was measured at 3-4-day intervals. Cultures were grown for 2 weeks, and the results of the experiments are presented in the graphs versus various concentrations of the tested monoterpenoids.

A mixture of three species of freshwater cyanobacteria and one selected isoprenoid derivative was used to determine the sensitivity of the cyanobacterial consortium to the monoterpenoid. For this purpose, experimental cultures were prepared as described above except that the volumes of cyanobacterial inocula placed in the flask were added such that each species composed $1 / 3$ of the final chlorophyll 

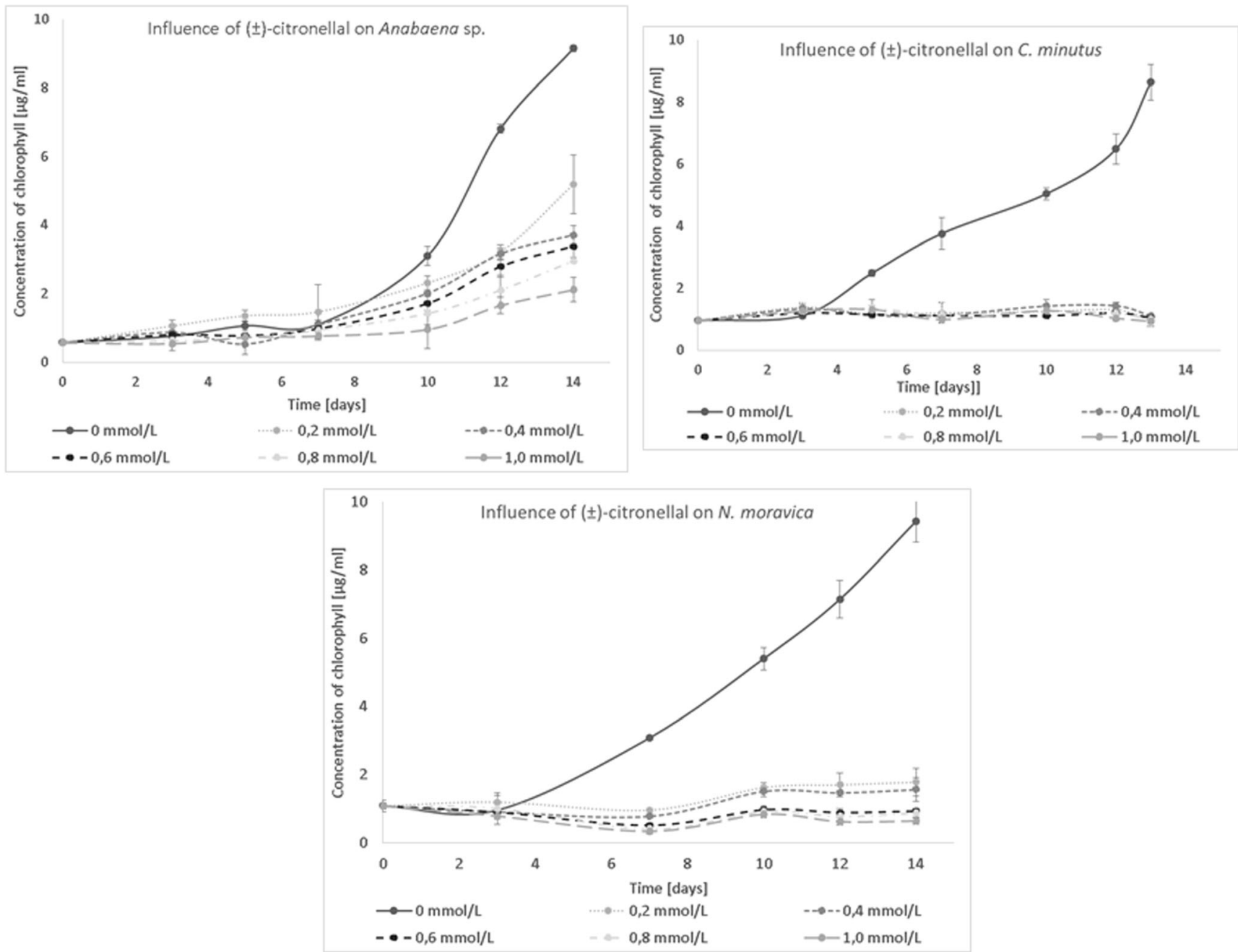

Fig. 2 Influence of ( \pm -citronellal on the growth of freshwater cyanobacteria

concentration of $1 \mu \mathrm{g} / \mathrm{mL}$. On the last day of the experiment, microscopic observations were made of the growth media.

To investigate the ability of cyanobacteria to biotransform monoterpenoids, experimental cultures were prepared as described above, and the final substrate concentration in the culture was $1.0 \mathrm{mmol} / \mathrm{L}$. The controls contained only the medium with dissolved monoterpenoid. The cultures were kept for 14 days in a room with constant lighting and temperature conditions. After 2 weeks, the contents of each flask were extracted 3 times with $25 \mathrm{~mL}$ of dichloromethane or chloroform. The organic phase was dried over anhydrous magnesium sulfate, and the solution was concentrated on a rotary evaporator. The obtained samples were subjected to TLC analysis and gas chromatography coupled to mass spectrometry (Hewlett-Packard 6890 Series coupled with hightemperature MS Hewlett-Packard 5073 with a $30 \mathrm{~m} \times$ $0.32 \mathrm{~mm}$ HP-5 capillary column) or GC-FID (Thermo Scientific with an HP-5 capillary column). The standard temperature program was (a) $40{ }^{\circ} \mathrm{C}$ for $5 \mathrm{~min}$, (b) $10.0{ }^{\circ} \mathrm{C} / \mathrm{min}$ from 40 to $190{ }^{\circ} \mathrm{C}$ and hold temperature for $5 \mathrm{~min}$, and (c) $20.0^{\circ} \mathrm{C} / \mathrm{min}$ from 190 to $250^{\circ} \mathrm{C}$ and hold temperature for 10 $\min$.

\section{Results}

Our studies verified an influence of selected monoterpenoids, including citral, $( \pm)$-citronellal, $( \pm)$-citronellol, eugenol, $(+)$ carvone, (+)-dihydrocarvone, $(+)$ - $\alpha$-pinene, eucalyptol, and $(+)-3$-carene, on the growth of the freshwater cyanobacteria species Anabaena sp., Chroococcus minutus, and Nodularia moravica.

\section{The influence of single monoterpenoids on the growth of cyanobacteria}

$N$. moravica was the most sensitive cyanobacterial species to the presence of citral; in this experiment, after 3 days, no growth was observed with citral concentrations of 0.8 and $1.0 \mathrm{mmol} / \mathrm{L}$. The growth of the other tested species was also 

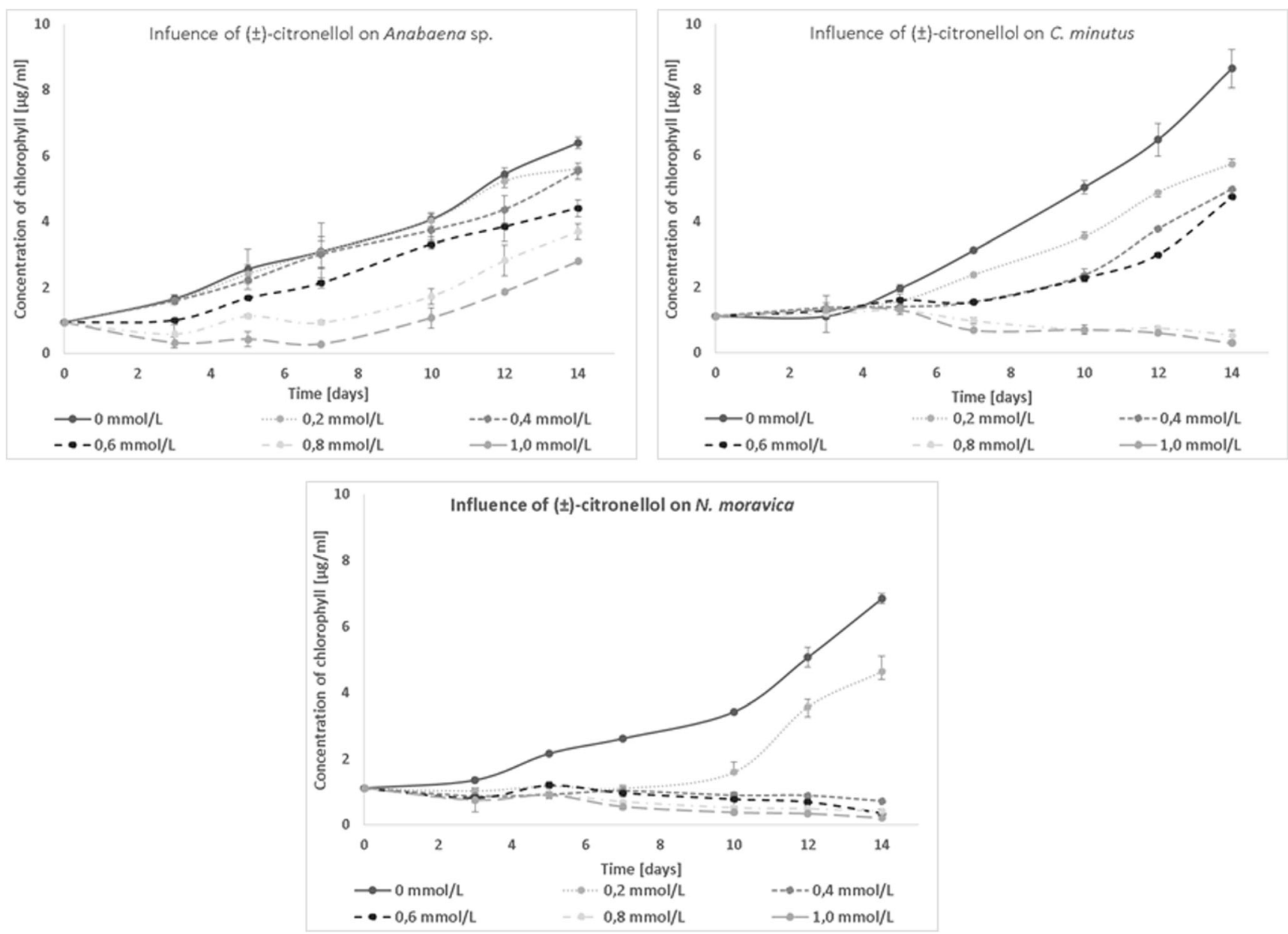

Fig. 3 Influence of $( \pm)$-citronellol on the growth of freshwater cyanobacteria

limited by citral; however, Anabaena sp. and C. minutus grew even with the highest concentration of citral (Fig. 1).

All tested species of blue-green algae were characterized by a similar type of sensitivity to the presence of $( \pm)$-citronellal. C. minutus and N. moravica showed limited growth in the early days of culturing. Consequently, the concentration of chlorophyll remained at $1 \mu \mathrm{g} / \mathrm{mL}$ until the last day of the experiment, the fourteenth (14th) day. The development of Anabaena sp. was also limited by $( \pm)$-citronellal, but at the lower tested concentration of this monoterpenoid, the chlorophyll content remained above $5 \mu \mathrm{g} / \mathrm{mL}$ (Fig. 2).

All tested blue-green algae were limited by $( \pm)$-citronellol. $N$. moravica was so sensitive that on the last day of culture, very little development was observed with almost all tested concentrations of this compound; only with $0.2 \mathrm{mmol} / \mathrm{L}$ of $( \pm)$-citronellol was growth visible. C. minutus was also limited by this compound; only with $0.2,0.4$, and $0.6 \mathrm{mmol} / \mathrm{L}$ of $( \pm)$ citronellol was growth observed (Fig. 3).

The presence of eugenol in the $C$. minutus culture caused significant inhibition of development with all tested concentrations. $N$. moravica also showed limited growth, but when lower concentrations of eugenol were used, more development was observed than in the control. On the other hand, Anabaena sp. showed increased growth with all tested concentrations of this compound compared with the control (Fig. 4).

The influence of (+)-carvone was also investigated. This compound strongly inhibited the growth of all examined cyanobacteria. Anabaena sp. and N. moravica showed limited growth with all tested concentrations of this added compound, and their development was further reduced when the concentrations increased. The growth of $C$. minutus was inhibited so strongly that even with the lower concentration of (+)-carvone tested, after 3 days of incubation, no development was observed, and after 14 days of cultivation, the culture was dead (Fig. 5). (+)Carvone was transformed to (+)-dihydrocarvone by all tested blue-green algae and to dihydrocarveol by Anabaena sp. (+)Dihydrocarvone was a detoxification product. To study the influence of (+)-dihydrocarvone on cyanobacterial growth, an isomeric mixture of $\sim 77 \% n$-(+)-dihydrocarvone and $\sim 20 \%$ iso-(+ )-dihydrocarvone was used. This mixture had a smaller influence on the growth of Anabaena sp. and C. minutus. N. moravica developed similarly to how it did in the presence of (+)-carvone. These results showed that blue-green algae activated cell defense 

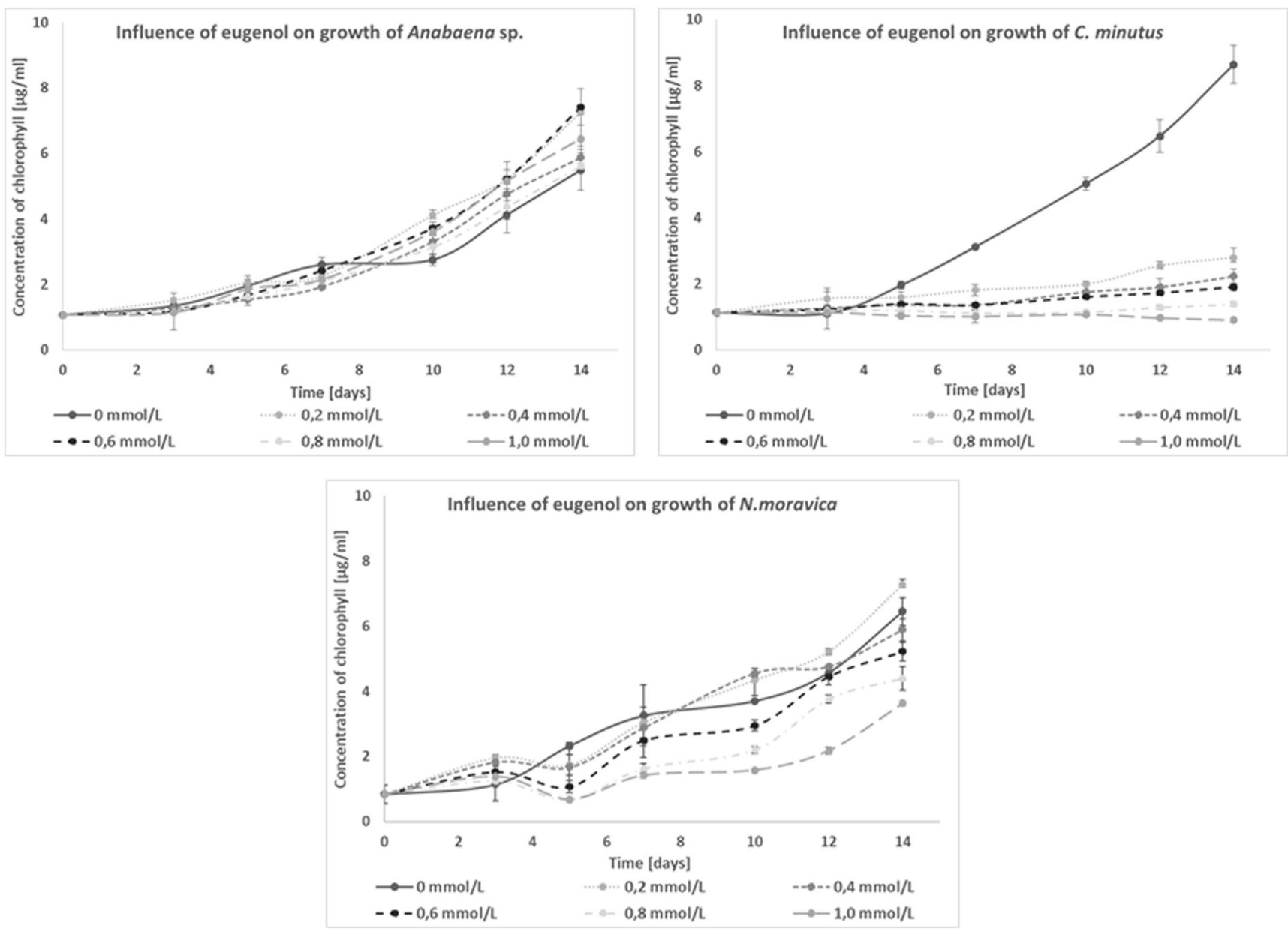

Fig. 4 Influence of eugenol on the growth of freshwater cyanobacteria

functions in an effort to transform more-toxic compounds into less harmful forms (Fig. 6).

(+)- $\alpha$-Pinene reduced the development of $C$. minutus, Anabaena sp., and $N$. moravica at all tested concentrations. The most sensitive species was $C$. moravica - even the lower concentrations of (+)- $\alpha$-pinene inhibited its development (Fig. 7).

Another tested compound was eucalyptol, which inhibited the growth of C. minutus and Anabaena sp. On the other hand, $N$. moravica was the only species whose growth increased with all tested concentrations of eucalyptol (Fig. 8).

In these tests, the best inhibitor of blue-green algae development was (+)-3-carene. It decreased the growth of $C$. minutus and $N$. moravica so strongly that very low chlorophyll contents were measured with all tested concentrations. $N$. moravica died after 14 days of culture. Only the development of Anabaena sp. was reduced by all tested concentrations of (+)-3-carene (Fig. 9).

\section{The influence of monoterpenoids on the growth of a cyanobacterial consortium}

In this work, the term "cyanobacterial consortium" refers to a mixed culture of freshwater cyanobacteria, Anabaena sp.,
C. minutus, and N. moravica, where the total chlorophyll concentration on day 0 was $1 \mu \mathrm{g} / \mathrm{mL}$, the result of combining of all three species such that each strain contributed $1 / 3$ of the initial concentration of chlorophyll.

The development of individual species of cyanobacteria and the consortium composed of these phototrophs is presented in Fig. 10. All three tested cyanobacterial species grew much better in their mutual presence-in the form of a consortium - than they did when cultured separately. This synergistic development enabled us to investigate the influence of selected monoterpenoids on the growth of the consortium comprising Anabaena sp., C. minutus, and N. moravica.

The development of a mixed culture of cyanobacteria in the presence of $(+)-\alpha$-pinene was significantly reduced even at the lowest applied monoterpenoid concentration. Levels of $(+)-\alpha-$ pinene of $0.6,0.8$, and $1.0 \mathrm{mmol} / \mathrm{L}$ best restricted the growth of the cyanobacterial consortium. A comparison of data on the growth of individual species and the consortium with added $(+)-\alpha$-pinene showed limited development of the mixture with increased monoterpenoid concentrations. An interesting result was obtained with Anabaena sp., as the species was less sensitive than were other cyanobacteria. Although microscopic 

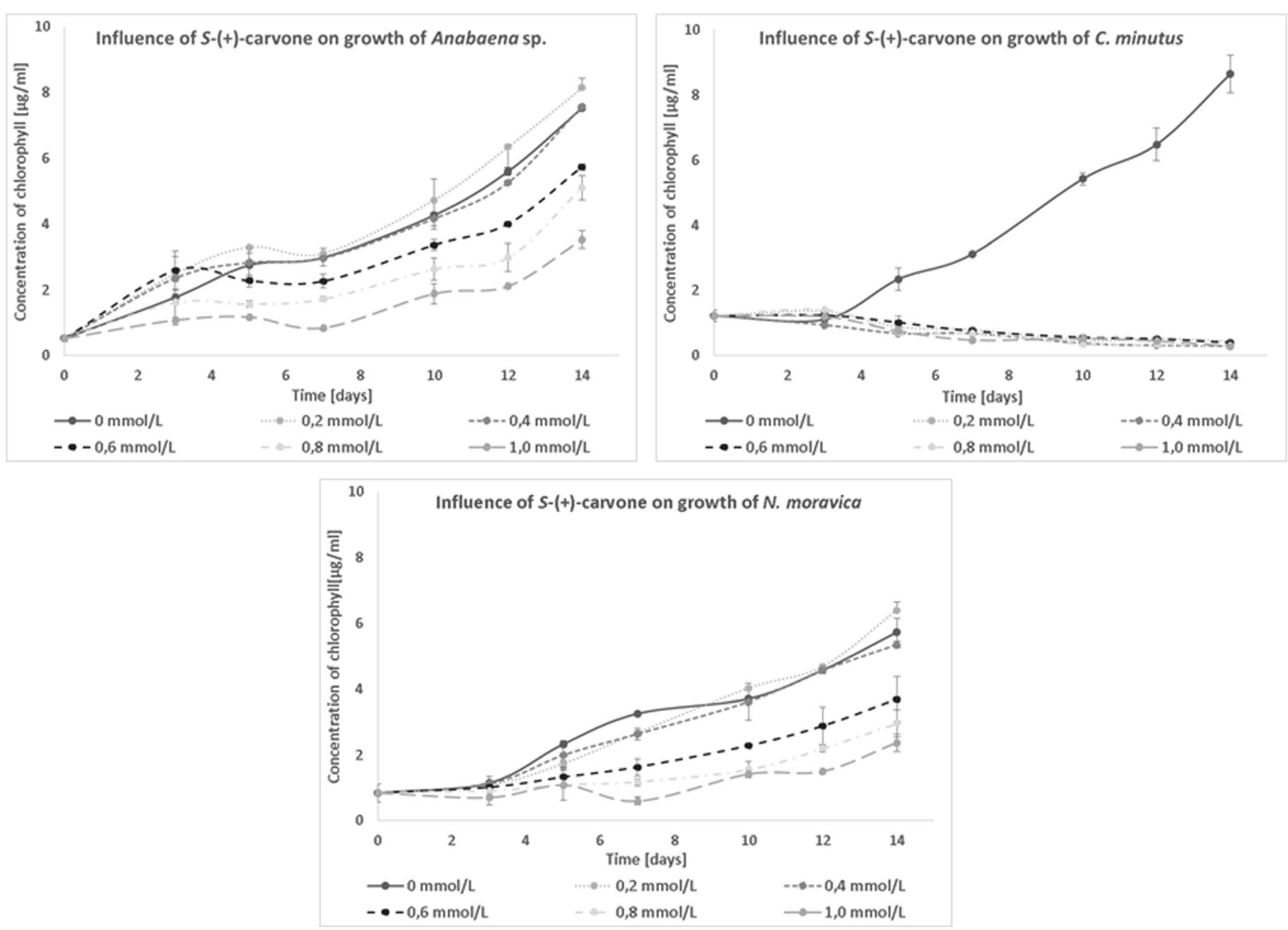

Fig. 5 Influence of (+)-carvone on the growth of freshwater cyanobacteria

observations showed the presence of each tested species, both in the control and with all concentrations of the studied monoterpenoid, the percentage change in the individual species in the consortium reflects their specific sensitivity to the tested compound. Notably, $(+)-\alpha$-pinene more effectively inhibited the development of cyanobacteria, which, as in natural conditions, grow in multispecies consortia instead of individual isolates of the studied species (Fig. S2).

A citral concentration of $1.0 \mathrm{mmol} / \mathrm{L}$ in the cyanobacterial consortium culture led to the virtual death of the culture after 5 days. The data analysis presented in Figure S3 suggests that the higher the concentration of added monoterpenoid, the better the reduction. The cyanobacterial consortium was much more sensitive to citral than were the cultures of individual cyanobacteria. Only $N$. moravica exhibited similar properties in its growth individually and in the mixture. A very interesting result was obtained at a concentration $1.0 \mathrm{mmol} / \mathrm{L}$ citral. The consortium was virtually dead in this condition, but single cultures of Anabaena sp. and C. minutus were still normal. These results suggest antagonism in the mixture of cyanobacteria in the presence of citral. The microscopic observations conducted in this case also confirmed the presence of each species tested, both in the control and at all concentrations of the monoterpenoid. However, the consortium was more sensitive to citral than were the individual species that formed the culture.

Another tested compound was $( \pm)$-citronellal, which reduced the growth of the cyanobacterial consortium as the concentrations of this monoterpenoid increased. A $( \pm)$-citronellal concentration of $0.4 \mathrm{mmol} / \mathrm{L}$ resulted in significantly less growth than a concentration of $0.2 \mathrm{mmol} / \mathrm{L}$. At this concentration, the development of the cyanobacterial mixture was practically identical to that of the control. The growth of freshwater cyanobacteria and their consortium with respect to the control with $( \pm)$-citronellal additive suggests that the development of a single species of Anabaena sp. is better than that of the cyanobacterial consortium with each of the tested concentrations. The growth of individual $N$. moravica and C. minutus cultures was considerably reduced up to approximately 80 $90 \%$ over the control with $( \pm)$-citronellal. The results at the 1 $\mathrm{mmol} / \mathrm{L}$ concentration showed a decrease in the development of the cyanobacterial consortium to approximately $10 \%$, and this value was practically the same for $N$. moravica and C. minutus growth but differed significantly from that of 


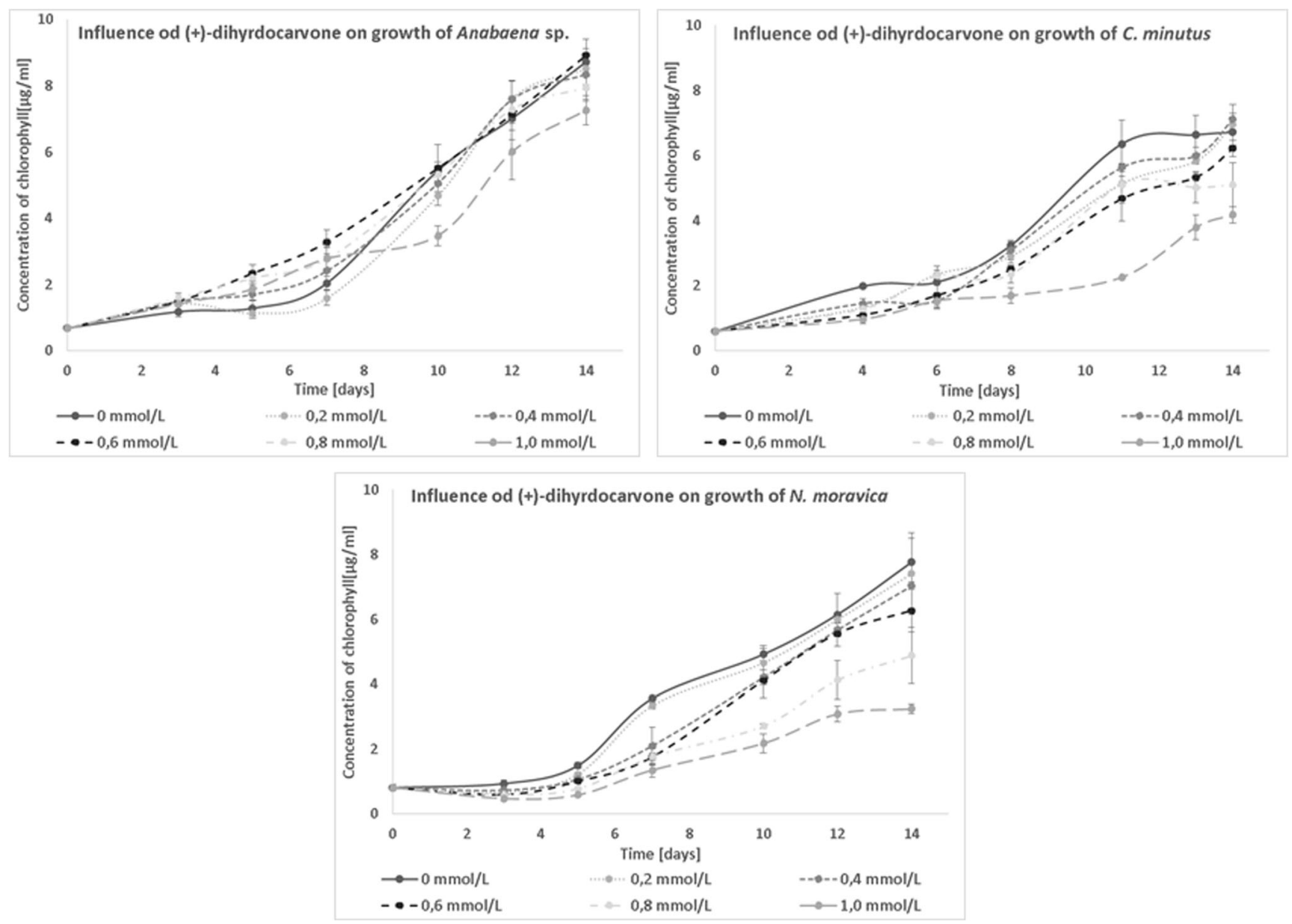

Fig. 6 Influence of (+)-dihydrocarvone on the growth of freshwater cyanobacteria

Anabaena sp. The microscopic observations of the consortium showed the presence of each of the species tested, both in the control and with all concentrations of the monoterpenoid studied; the percentage change in the individual species in the consortium reflected their specific sensitivity to the test compound (Fig. S4).

$( \pm)$-Citronellol, similar to previously reported results, limited the development of the cyanobacterial consortium. Concentrations of $0.2,0.4$, and $0.6 \mathrm{mmol} / \mathrm{L}$ of this compound only slightly decreased cyanobacterial growth. The highest introduced concentration of $( \pm)$-citronellol essentially resulted in the inhibition of consortium growth by the 5th day of culture (Fig. S5). Cyanobacterial consortium development increased relative to that of the individual cyanobacteria in the presence of 0.2 and $0.6 \mathrm{mmol} / \mathrm{L}( \pm)$-citronellol. The situation changed at a concentration of $1.0 \mathrm{mmol} / \mathrm{L}$, where there was much better development of Anabaena sp. individually than in the consortium. At this concentration, the consortium was significantly inhibited. In addition, microscopic observations showed the presence of each of the examined species, both in the control and with all concentrations of the tested monoterpenoid.
The cyanobacterial consortium culture containing eugenol showed only slightly reduced development (Fig. S6). With low concentrations of eugenol, cyanobacterial development was similar to that under control cultures, whereas individual Anabaena sp. and N. moravica cultures developed more strongly than the controls. On the other hand, only the growth of Anabaena sp. was intensified. Interestingly, eugenol added even at the highest tested concentration did not limit the development of the cyanobacterial consortium as much as the other compounds did. The most sensitive species was $C$. minutus. The smaller dynamics of change in the consortium indicates the stabilizing role of interactions within the multispecies population in the presence of these external chemical inputs.

Similarly to the aforementioned eugenol, (+)-3-carene showed no ability to limit the development of the cyanobacterial consortium. Concentrations from 0.2 to $0.6 \mathrm{mmol} / \mathrm{L}$ mildly enhanced the development of the culture (Fig. S7). In comparing the consortium and individual cyanobacterial cultures, the consortium exhibited increased (+)-3-carene resistance, as was the case with eugenol. The simultaneous presence of all three tested species likely results in undefined synergy in response to the presence of this mono-oxidant. Microscopic images showed 

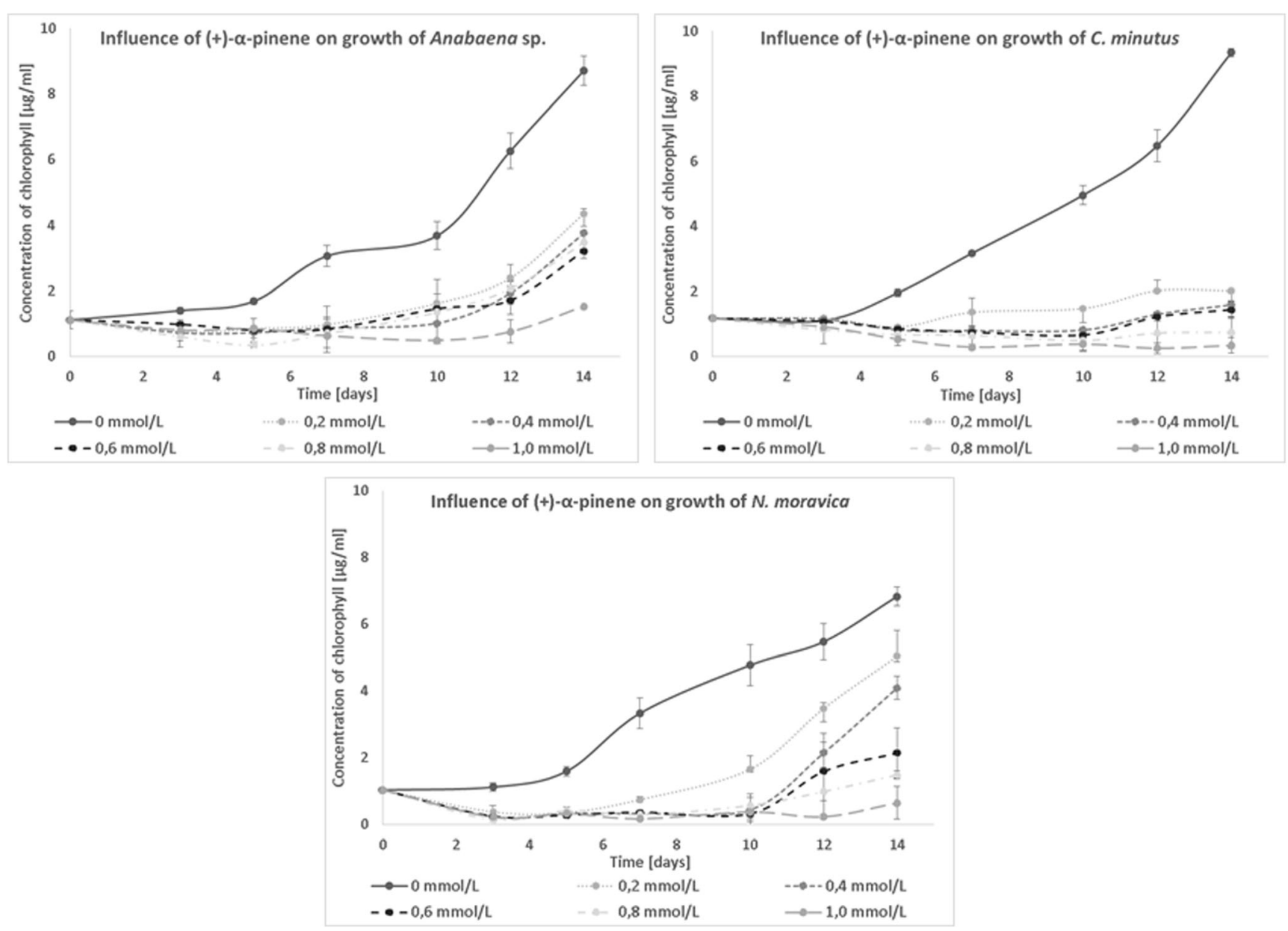

Fig. 7 Influence of (+)- $\alpha$-pinene on the growth of freshwater cyanobacteria

the presence of all cyanobacteria, both in the control and in test cultures with added (+)-3-carene.

Adding progressively more (+)-carvone to cultures of the cyanobacterial consortium progressively reduced growth up to approximately $60 \%$. At the lowest of the tested concentrations, monoclonal cultures of Anabaena sp. and N. moravica showed increased development relative to the control, but as the (+)-carvone concentration increased, the cyanobacteria decreased in the consortium and in individual cultures. Notably, even then, Anabaena sp. and N. moravica grown separately developed better than they did in the consortium. These results suggest that this compound is a growth inhibitor in all types of tested cyanobacteria. Although microscopic observations showed the presence of each species tested, both in the control and at all concentrations of the monoterpenoid studied, the percentage changes in the individual species in the consortium reflected their specific susceptibility to (+)-carvone (Fig. S8).

\section{Biotransformation}

None of the tested cyanobacteria measurably biotransformed citral, $( \pm)$-citronellal, $( \pm)$-citronellol, eugenol, $(+)-\alpha$-pinene, eucalyptol, and of (+)-3-carene. Only (+)-carvone was transformed by all tested blue-green algae. The main product of this process was (+)-dihydrocarvone; only Anabaena sp. also produced (+)-dihydrocarveol. this is a surprising result of the lack of greater biotransformation capacity of monoterpene compounds, as literature data indicate such capacity (Balcerzak et al. 2014).

\section{Discussion}

In this paper, we examined the influence of monoterpenoids, including citral, $( \pm)$-citronellal, $( \pm)$-citronellol, eugenol, $(+)$ carvone, (+)-dihydrocarvone, $(+)-\alpha$-pinene, eucalyptol, and $(+)-3$-carene, on the growth of the freshwater cyanobacteria Anabaena sp., Chroococcus minutus, and Nodularia moravica. We demonstrated that some monoterpenoids, such as $\alpha$-pinene and (+)-carvone, can inhibit the growth of Anabaena sp., Chroococcus minutus, and Nodularia moravica. The extent of the inhibitory effect depended on the concentration of the added compound and the type of species. Nodularia moravica was inhibited the best by (+)-3- 

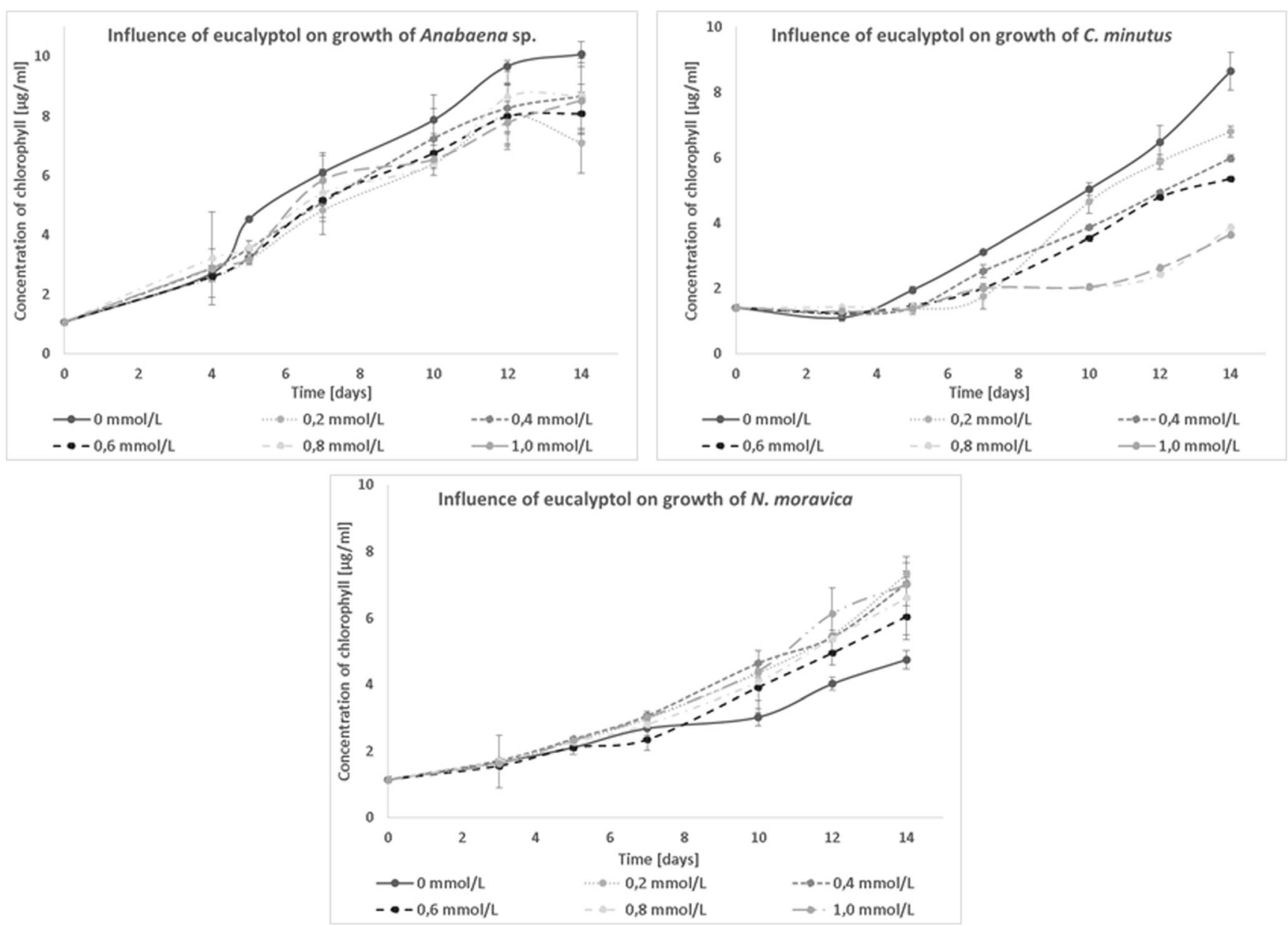

Fig. 8 Influence of eucalyptol on the growth of freshwater cyanobacteria

carene, and eucalyptol increased the growth of this cyanobacterium.

Chroococcus minutus proved to be the most susceptible to the influence of the examined monoterpenes. It was strongly inhibited by $(+)$-carvone, $( \pm)$-citronellal, eugenol, $(+)-\alpha$-pinene, and (+)-3-carene. However, citral, (-)-fenchone, and eucalyptol only slightly inhibited the growth of Chroococcus minutus when the concentration of the added monoterpenes increased.

Anabaena sp. displayed less growth when the concentration of added (+)-carvone, $\alpha$-pinene, or $(+)-3$-carene increased. On the other hand, eugenol caused the accelerated growth of Anabaena sp. This species was the most resistant to the presence of the tested monoterpenoids.

Studies conducted on freshwater cyanobacterial consortia have demonstrated the synergism of the development of the mixture of Anabaena sp., Chroococcus minutus, and Nodularia moravica. In the case of this consortium, adding monoterpenoids limited development. Interesting results were obtained with (+)-3-carene, which, contrary to earlier results, led to the development of the cyanobacterial consortium. Most of the tested compounds inhibit the development of cyanobacteria, even when microorganisms develop in multispecies consortia, as in natural conditions, rather than in the individual species studied. Citral and (+)- $\alpha$-pinene much more effectively inhibit the growth of cyanobacteria growing in the consortium than they do the growth of cultures with particular species.

To date, only the influence of essential oils and one monoterpen on the growth of cyanobacteria has been examined. Zhao et al. (2020) presented the physiological and molecular inhibition effect of eugenol on Microcystis aeruginosa. Eugenol had great potential for inhibition of the cell density of this cyanobacterium with increasing concentration (Zhao et al. 2020). There were obtained similar results for Chroococcus minutus. While the development of tested Anabaena sp. was not enhance in the presence of eugenol. This confirm our observation that the inhibitory activity of this compound largery depends on the type of examined cyanobacteria. Thus, Najem et al. (2016) reviewed the allelopathic activity of essential oils obtained from Rosmarinus officinalis L. on Microcystis aeruginosa and Chroococcus minor (Najem et al. 2016). In 2015, Wang et al. investigated the inhibitory effect of essential oils from six submerged 

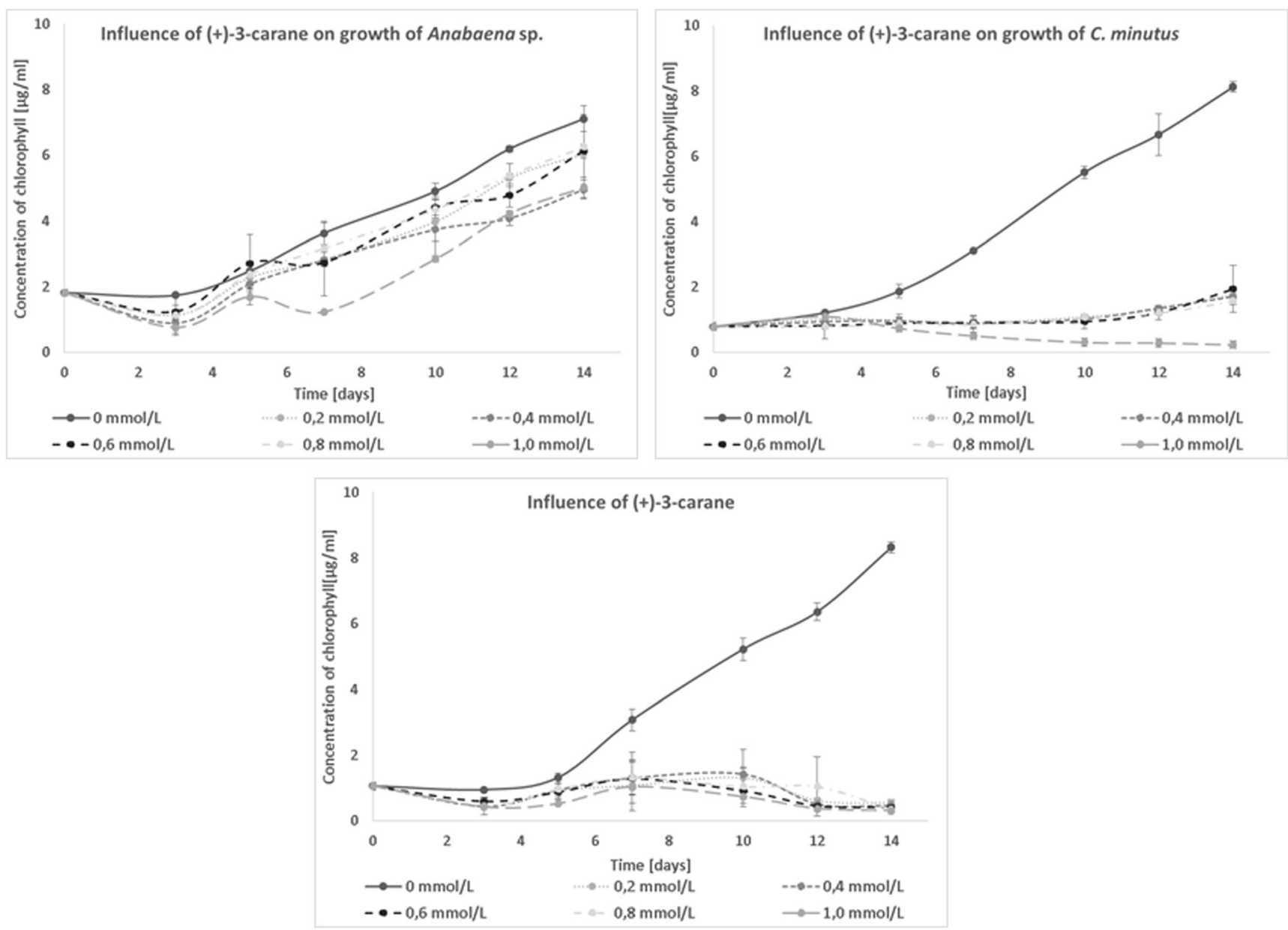

Fig. 9 Influence of (+)-3-carane on the growth of freshwater cyanobacteria

macrophytes (Potamogeton cristatus, Potamogeton maackianus, Potamogeton lucens, Vallisneria spinulosa, Ceratophyllum demersum, and Hydrilla verticillate) on the growth of Microcystis aeruginosa, and the inhibition ratio

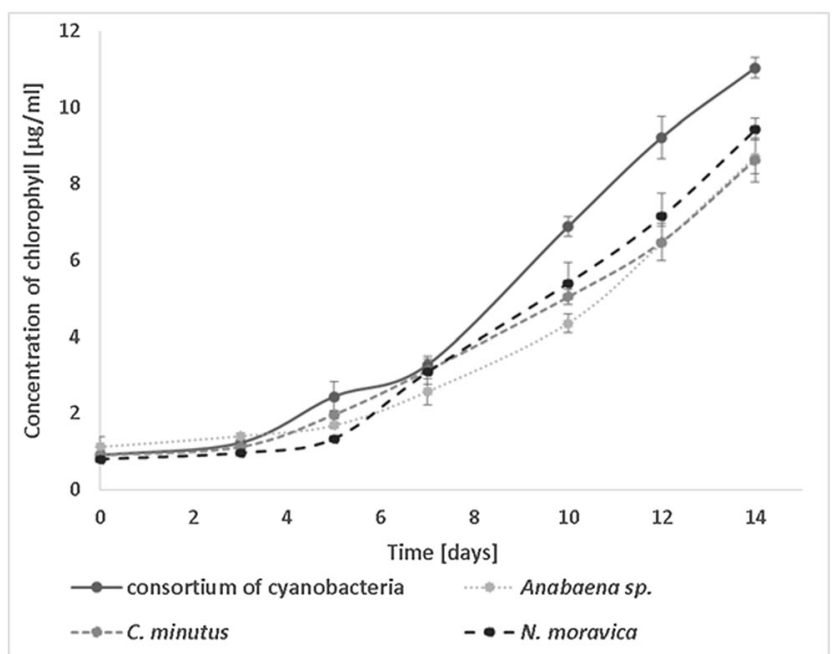

Fig. 10 Growth of single freshwater blue-green algae and cyanobacterial consortium was 30-40\% (Wang et al. 2015); essential oils from Arundo donax and Typha latifolia were also investigated as growth inhibitors of these species of cyanobacteria (Wang et al. 2014). Tellez et al. (2000) reported that essential oils from Callicarpa americana are good inhibitors of the growth of Oscillatoria perornata (Tellez et al. 2000). Moreover, Zerrifi et al. (2020a, 2020b) investigated essential oils from seaweed (Cystoseira tamariscifolia, Sargassum muticum, and Ulva lactuca) against Microcystis aeruginosa, and only one of them, Cystoseira tamariscifolia, inhibited the growth of this cyanobacteria (Zerrifi et al. 2020a, 2020b). In another publication in 2020, Zerrifi et al. used essential oils from Moroccan plants (Chenoporium ambrosioides, Thymus broussonetii, Thymus maroccanus, Thymus pallidus, Thymus satureioides, Satureja calamintha L., and Mentha suaveolens L.) to investigate anticyanobacterial activity, and all of the studied EOs presented interesting activities against Microcystis aeruginosa (Zerrifi et al. 2020a, 2020b). Essential oils (EOs) are volatile, natural, complex compounds characterized by a strong odor and are synthesized by aromatic plants as secondary metabolites. Plants produce them to protect themselves against bacteria, viruses, fungi, insects, and herbivores by reducing their 
appetite for such plants. Essential oils are very complex and can contain as many as 60 components in different concentrations, but they are mainly characterized by two or three major components whose concentrations can account for as much as $70 \%$ of the EO. Terpenes and terpenoids are the main groups composing essential oils; for example, carvone makes up 58\% and limonene makes up 37\% the essential oils of the seed Anethum graveolens (Bakkali et al. 2008). Thus, in this article, we presented the interaction of individual terpenoids, and it can be concluded that individual components of essential oils are responsible for the inhibition or increased development of cyanobacteria.

In summary, the inhibitory effect depends on the types of added monoterpenoids and cyanobacteria. The best inhibitor and the most vulnerable cyanobacteria cannot be individually selected. Moreover, the present results can contribute to creating natural-origin products that will clear backyard ponds of bloom formations or call the attention of the cosmetic industry to use flavorings more carefully because they can pollute the water and enhance the growth of cyanobacteria.

Supplementary Information The online version contains supplementary material available at https://doi.org/10.1007/s00253-021-11260-8.

Author contribution LB performed the experiments and prepared the manuscript. LB and JL analyzed the data. SL and JL supervised the work and provided critical revisions to the manuscript. All authors have approved the final version. All authors agree to take responsibility for the accuracy and integrity of the research.

Data availability All data generated or analysed during this study are included in this published article.

\section{Declarations}

Human and Animal Rights and informed Concent This article does not contain any studies with human participants or animals performed by any of the authors.

Conflict of interest The authors declare no competing interests.

Open Access This article is licensed under a Creative Commons Attribution 4.0 International License, which permits use, sharing, adaptation, distribution and reproduction in any medium or format, as long as you give appropriate credit to the original author(s) and the source, provide a link to the Creative Commons licence, and indicate if changes were made. The images or other third party material in this article are included in the article's Creative Commons licence, unless indicated otherwise in a credit line to the material. If material is not included in the article's Creative Commons licence and your intended use is not permitted by statutory regulation or exceeds the permitted use, you will need to obtain permission directly from the copyright holder. To view a copy of this licence, visit http://creativecommons.org/licenses/by/4.0/.

\section{References}

Alwathnani H, Johansen JR (2011) Cyanobacteria in soils from a Mojave Desert Ecosystem. Monographs of the Western North American Naturalist 71-89:19-89. https://doi.org/10.3398/042.005.0103

Bakkali F, Averbeck S, Averbeck D, Idaomar M (2008) Biological effects of essential oils - a review. Food Chem Toxicol 46:446-475. https://doi.org/10.1016/j.fct.2007.09.106

Balcerzak L, Lipok J, Strub D, Lochyński S (2014) Biotransformations of monoterpenes by photoautotrophic micro-organisms. J Appl Microbiol 117:1523-1536. https://doi.org/10.1111/jam.12632

Bittencourt-Oliveira MC, Buch B, Hereman T, Arruda-Neto J, Moura A, Zocchi S (2012) Effects of light intensity and temperature on Cylindrospermopsis raciborskii (Cyanobacteria) with straight and coiled trichomes: Growth rate and morphology. Braz J Biol 72: 343-351. https://doi.org/10.1590/S1519-69842012000200016

Bláhová L, Adamovský O, Kubala L, Švihálková Šindlerová L, Zounková R, Bláha L (2013) The isolation and characterization of lipopolysaccharides from Microcystis aeruginosa, a prominent toxic water bloom forming cyanobacteria. Toxicon 76:187-196. https:// doi.org/10.1016/j.toxicon.2013.10.011

Bonilla S, Aubriot L, Soares MC, González-Piana M, Fabre A, Huszar VL, Lürling M, Antoniades D, Padisák J, Kruk C (2012) What drives the distribution of the bloom-forming cyanobacteria Planktothrix agardhii and Cylindrospermopsis raciborskii? FEMS Microbiol Ecol 79:594-607. https://doi.org/10.1111/j.1574-6941. 2011.01242.x

Codd GA (2000) Cyanobacterial toxins, the perception of water quality, and the prioritisation of eutrophication control. Ecol Eng 16:51-60. https://doi.org/10.1016/S0925-8574(00)00089-6

Dai G-Z, Shang J-L, Qiu B-S (2012) Ammonia may play an important role in the succession of cyanobacterial blooms and the distribution of common algal species in shallow freshwater lakes. Glob Chang Biol 18:1571-1581. https://doi.org/10.1111/j.1365-2486.2012. 02638.x

Dawson RM (1998) The toxicology of microcystins. Toxicon 36:953962. https://doi.org/10.1016/s0041-0101(97)00102-5

de Figueiredo DR, Azeiteiro UM, Esteves SM, Gonçalves FJM, Pereira MJ (2004) Microcystin-producing blooms - a serious global public health issue. Ecotoxicol Environ Saf 59:151-163. https://doi.org/10. 1016/j.ecoenv.2004.04.006

de Souza Santos RK, Rios Jacinavicius F, Leite Sant'Anna CJF (2011) Effects of the $\mathrm{pH}$ on growth and morphology of Anabaenopsis elenkinii Miller (Cyanobacteria) isolated from the alkaline shallow lake of the Brazilian Pantanal. Fottea 11:119-126. https://doi.org/ $10.5507 /$ fot.2011.012

Degenhardt J, Köllner TG, Gershenzon J (2009) Monoterpene and sesquiterpene synthases and the origin of terpene skeletal diversity in plants. Phytochemistry 70:1621-1637. https://doi.org/10.1016/j. phytochem.2009.07.030

Fan G, Bao M, Zheng X, Hong L, Zhan J, Chen Z, Qu F (2019) Growth inhibition of harmful cyanobacteria by nanocrystalline $\mathrm{Cu}-\mathrm{MOF}-74$ : efficiency and its mechanisms. J Hazard Mater 367:529-538. https://doi.org/10.1016/j.jhazmat.2018.12.070

Fay P (1965) Heterotrophy and nitrogen fixation in Chlorogloea fritschii. J Gen Microbiol 39:11-20. https://doi.org/10.1099/00221287-39-111

Groussin A-L, Antoniotti S (2012) Valuable chemicals by the enzymatic modification of molecules of natural origin: terpenoids, steroids, phenolics and related compounds. Bioresour Technol 115:237243. https://doi.org/10.1016/j.biortech.2011.10.050

Harke MJ, Berry DL, Ammerman JW, Gobler CJ (2012) Molecular response of the bloom-forming cyanobacterium, Microcystis aeruginosa, to phosphorus limitation. Microb Ecol 63:188-198. https://doi.org/10.1007/s00248-011-9894-8 
Heisler JP, Glibert P, Burkholder J, Anderson D, Cochlan W, Dennison W, Dortch Q, Gobler C, Heil C, Humphries E, Lewitus A, Magnien R, Marshall H, Sellner K, Stockwell DA, Stoecker D, Suddleson M (2008) Eutrophication and harmful algal blooms: a scientific consensus. Harmful Algae 8:3-13. https://doi.org/10.1016/j.hal.2008. 08.006

Jiang Z, Liu J, Chen J, Chen Q, Yan X, Xuan J, Zeng J (2014) Responses of summer phytoplankton community to drastic environmental changes in the Changjiang (Yangtze River) estuary during the past 50 years. Water Res 54:1-11. https://doi.org/10.1016/j.watres.2014. 01.032

Jurczak T, Tarczynska M, Izydorczyk K, Mankiewicz J, Zalewski M, Meriluoto J (2005) Elimination of microcystins by water treatment processes - examples from Sulejow Reservoir, Poland. Water Res 39:2394-2406. https://doi.org/10.1016/j.watres.2005.04.031

Kormas KA, Gkelis S, Vardaka E, Moustaka-Gouni M (2011) Morphological and molecular analysis of bloom-forming Cyanobacteria in two eutrophic, shallow Mediterranean lakes. Limnologica 41:167-173. https://doi.org/10.1016/j.limno.2010.10. 003

Le Rouzic B, Thiébaut G, Brient L (2016) Selective growth inhibition of cyanobacteria species (Planktothrix agardhii) by a riparian tree leaf extract. Ecol Eng 97:74-78. https://doi.org/10.1016/j.ecoleng.2016. 07.021

Li R, Huang H, Wang JJ, Liang W, Gao P, Zhang Z, Xiao R, Zhou B, Zhang X (2019) Conversion of $\mathrm{Cu}$ (II)-polluted biomass into an environmentally benign $\mathrm{Cu}$ nanoparticles-embedded biochar composite and its potential use on cyanobacteria inhibition. J Clean Prod 216:25-32. https://doi.org/10.1016/j.jclepro.2019.01.186

Najem AM, Abed IJ, Al-haidari AMD (2016) Evaluation the activity of rosemary (Rosmarinus officinalis L.) essential oil against some cyanobacteria. Iraqi J. Biotechnol. 15:97-102

Nimptsch J, Wiegand C, Pflugmacher S (2008) Cyanobacterial toxin elimination via bioaccumulation of MC-LR in aquatic macrophytes: an application of the "Green Liver Concept". Environ Sci Technol 42:8552-8557. https://doi.org/10.1021/es8010404

O'Neil JM, Davis TW, Burford MA, Gobler CJ (2012) The rise of harmful cyanobacteria blooms: the potential roles of eutrophication and climate change. Harmful Algae 14:313-334. https://doi.org/10. 1016/j.hal.2011.10.027

Paerl HW, Paul VJ (2012) Climate change: links to global expansion of harmful cyanobacteria. Water Res 46:1349-1363. https://doi.org/ $10.1016 /$ j.watres.2011.08.002

Porra RJ (2002) The chequered history of the development and use of simultaneous equations for the accurate determination of chlorophylls a and b. Photosynth Res 73:149-156. https://doi.org/10. 1023/A:1020470224740

Rastogi RP, Sinha RP (2009) Biotechnological and industrial significance of cyanobacterial secondary metabolites. Biotechnol Adv 27:521539. https://doi.org/10.1016/j.biotechadv.2009.04.009

Rothschild LJ, Mancinelli RL (2001) Life in extreme environments. Nature 409:1092-1101. https://doi.org/10.1038/35059215
Schopf JW (2012) Ecology of cyanobacteria II: their diversity in space and time. 17-19

Sharma VK, Triantis TM, Antoniou MG, He X, Pelaez M, Han C, Song W, O'Shea KE, de la Cruz AA, Kaloudis T, Hiskia A, Dionysiou DD (2012) Destruction of microcystins by conventional and advanced oxidation processes: a review. Sep Purif Technol 91:3-17. https://doi.org/10.1016/j.seppur.2012.02.018

Sinha R, Pearson LA, Davis TW, Burford MA, Orr PT, Neilan BA (2012) Increased incidence of Cylindrospermopsis raciborskii in temperate zones-is climate change responsible? Water Res 46:1408-1419. https://doi.org/10.1016/j.watres.2011.12.019

Soares MCS, Lürling M, Huszar VLM (2013) Growth and temperaturerelated phenotypic plasticity in the cyanobacterium Cylindrospermopsis raciborskii. Phycol Res 61:61-67. https://doi. org $/ 10.1111 /$ pre. 12001

Tellez MR, Dayan FE, Schrader KK, Wedge DE, Duke SO (2000) Composition and some biological activities of the essential oil of Callicarpa americana (L.). J Agric Food Chem 48:3008-3012. https://doi.org/10.1021/jf991026g

Vioque A (2007) Transformation of cyanobacteria. Adv Exp Med Biol 616:12-22. https://doi.org/10.1007/978-0-387-75532-8_2

Waajen G, Faassen E, Lurling M (2014) Eutrophic urban ponds suffer from cyanobacterial blooms: Dutch examples. Environ Sci Pollut Res Int 21:9983-9994. https://doi.org/10.1007/s11356-014-2948-y

Wang H-Q, Liang F, Qiao N, Dong J-X, Zhang L-Y, Guo Y-F (2014) Chemical composition of volatile oil from two emergent plants and their algae inhibition Activity. Pol J Environ Stud 23:2371-2374

Wang H, Liang F, Zhang L (2015) Composition and anti-cyanobacterial activity of essential oils from six different submerged macrophytes. Pol J Environ Stud 24:333-338. https://doi.org/10.15244/pjoes/ 26383

Zerrifi SEA, Kasrati A, Redouane EM, Tazart Z, Khalloufi FE, Abbad A, Oudra B, Campos A, Vasconcelos V (2020a) Essential oils from Moroccan plants as promising ecofriendly tools to control toxic cyanobacteria blooms. Ind Crop Prod 143:111922. https://doi.org/ 10.1016/j.indcrop.2019.111922

Zerrifi SA, Khalloufi FE, Mugani R, Mahdi RE, Kasrati A, Soulaimani B, Barros L, Ferreira ICFR, Amaral JS, Finimundy TC, Abbad A, Oudra B, Campos A, Vasconcelos V (2020b) Seaweed essential oils as a new source of bioactive compounds for cyanobacteria growth control: innovative ecological biocontrol approach. Toxins 12:527

Zhao P, Liu S, Huang W, He L, Li J, Zhou J, Zhou J (2020) Influence of eugenol on algal growth, cell physiology of cyanobacteria Microcystis aeruginosa and its interaction with signaling molecules. Chemosphere 255:126935. https://doi.org/10.1016/j.chemosphere. 2020.126935

Publisher's note Springer Nature remains neutral with regard to jurisdictional claims in published maps and institutional affiliations. 